\title{
PERFORMANCE EVALUATION OF SOLAR AIR COLLECTOR BY CHIMNEY EFFECT FOR DRYING APPLICATIONS
}

\author{
Gedion Habtay GEBREMICHEAL, Janos BUZAS, István FARKAS* \\ Hungarian University of Agriculture and Life Sciences, Gödöllő, Hungary
}

\begin{abstract}
Solar air collector is one of the main components of a solar dryer unit, which supplies the conditioned air for processing the perishable edible items. Various techniques have been employed to improve the thermal efficiency of the collector system, such as extended surfaces, packed beds, artificial roughness, etc., however, the cost of construction is higher. Therefore, this study was focussed on the collector efficiency enhancement using a chimney without applying the aforementioned. A single-pass solar air collector coupled with drying chamber and chimney was utilized for the experiments. The experiments were conducted in September. The average values of the solar radiation intensity, ambient temperature, temperatures inside the dryer, collector efficiency were graphically presented. The experimental data reported the maximum values of the outlet temperatures for the solar air collector with and without a chimney to be $52.8{ }^{\circ} \mathrm{C}$ and $57{ }^{\circ} \mathrm{C}$, respectively. The collector thermal efficiency with and without the chimney was found to vary from $29.6 \%$ to $64.8 \%$ and from $26.9 \%$ to $44.8 \%$, respectively. Furthermore, it was noticed that, with the chimney, the temperature inside the dryer showed uniform tendency.
\end{abstract}

Keywords: chimney; experiment; efficiency; single-pass solar collector; indirect solar dryer

Preservation of agricultural products is necessary to prolong the shelf life without compromising the quality. Sun drying method for drying agricultural products is one of the oldest methods used in the drying of crops. The technique is highly compromised by variations in ambient weather conditions, mainly in the form of abrupt changes in temperature and humidity (Ssewanga et al., 2020). The drying food product is often exposed to extreme temperatures during drying time. These limitations of the open sun drying method have led to the development of different types of dryers that use solar energy. The improvement scope in the design and operation of solar dryers that are generally classified into direct, indirect, and mixed-mode systems, has been found in the literature (Afriyie et al., 2009). The flow of dried air is either controlled by the buoyancy effect (density difference created by temperature difference), or a fan (forced circulation). Due to the absence of an external driving force (fan or blower), the natural indirect type of solar dryer system is economically viable (El-Sebaii et al., 2002). These dryers are equipped with a separate absorber to collect solar irradiation and preheat the air (solar air collector) (Madhlopa et al., 2002).

Considering the single-pass solar air collectors, there were reported poor thermal efficiency due to high heat losses, and low convective heat transfer coefficient between the absorber plate and the air stream (Ramani et al., 2010). Numerous researchers have tried to improve the thermal performance of the flat plate solar collectors by modifications to design and flow. Omojaro and Aldabbagh (2010) investigated the thermal performance of single and double-pass solar air heaters using a steel wire mesh as absorber plate, concluding that the efficiency increases with increasing airflow rate. The performance of three types of solar collectors, namely flat plate, finned and v-corrugated, have been evaluated experimentally by Karim and Hawlader (2004), who observed that the v-corrugated collector was the most efficient. Aldabbagh et al. (2010) developed a single and double pass solar air collectors with steel wire mesh layers instead of a flat absorber plate. The maximum efficiency of $45.93 \%$ was recorded for the single pass collector. El-Sebaii et al. (2007) reported that the thermal efficiency with gravel was $22-27 \%$ higher in contrast to the device without the packed bed. Chabane et al. (2013) evaluated a flat plate air collector using two mass flow rates of $0.012 \mathrm{~kg} \cdot \mathrm{s}^{-1}$ and $0.016 \mathrm{~kg} \cdot \mathrm{s}^{-1}$. The result indicated that the rise in thermal efficiency was a consequence of airflow rate increase. Another efficiency improvement has been achieved on the collector glazing sheet. Parikh and Agrawal (2012) used two types of glass - normal glass and polycarbonate sheet - as a glazing material for the solar air collector, observing that the efficiency increased to $23.7 \%$ with the glass cover and to $18.5 \%$ using the polycarbonate sheet.

The designing aspect of the natural convective dryers can be addressed if a chimney is retrofitted at the drying chamber top. A chimney integrated with a solar dryer increases the buoyancy force applied on the air stream for the purposes of enhancing the air flow rate. In a natural convection dryer, the air flow velocity depends on the flowing air temperature, chimney height and friction forces

Contact address: István Farkas, Hungarian University of Agriculture and Life Sciences, Páter K. u. 1, Gödöllő, H-2100 Hungary; e-mail: farkas.istvan@uni-mate.hu 
(Bouhdjar et al., 2020). A good chimney height and proper design were observed to have an impact on the volumetric flow rate of air through the drying system (Ong and Chow, 2003). The results of an earlier study (Habtay and Farkas, 2019) carried out on the chimney of an indirect passive solar dryer showed that the buoyancy force improved when the outer chimney surface was painted black. Lingayat et al. (2017) developed an indirect solar dryer for drying bananas. The system comprised a single-pass solar air collector, a drying chamber and a chimney. The experimental result suggested that the average collector thermal efficiency reached $31.50 \%$. A recent study (Lingayat et al., 2020) indicated that the average thermal efficiency of the collector was $56.3 \%$.

The aim of this paper is to evaluate the thermal performance of a solar air collector integrated with a chimney on top of the drying chamber while comparing the results with the output of the same dryer without a chimney. The amount of solar energy absorbed by the collector was also investigated. To conduct this study, data of solar incident, ambient temperature, air velocity and temperatures inside the solar dryer were continuously recorded on specified experimental days in September with a sufficient amount of solar radiation.

\section{Material and methods}

\section{Experimental setup}

The experimental setup used in this study is shown in Fig. 1. The experiment was conducted in the Solar Laboratory of the Hungarian University of Agriculture and Life Sciences (MATE) from September $1^{\text {st }}$ to $7^{\text {th }}, 2020$. The University is located in Gödöllő, Hungary ( $47^{\circ} 35^{\prime} 51^{\prime \prime} \mathrm{N}$ latitude, $19^{\circ} 20^{\prime} 53^{\prime \prime}$ E longitude). Gödöllő has a temperate oceanic climate based on the Koppen climate classification with summer average temperatures ranging from $15^{\circ} \mathrm{C}$ to $26{ }^{\circ} \mathrm{C}$, winter from $-3{ }^{\circ} \mathrm{C}$ to $3{ }^{\circ} \mathrm{C}$ and the mean monthly

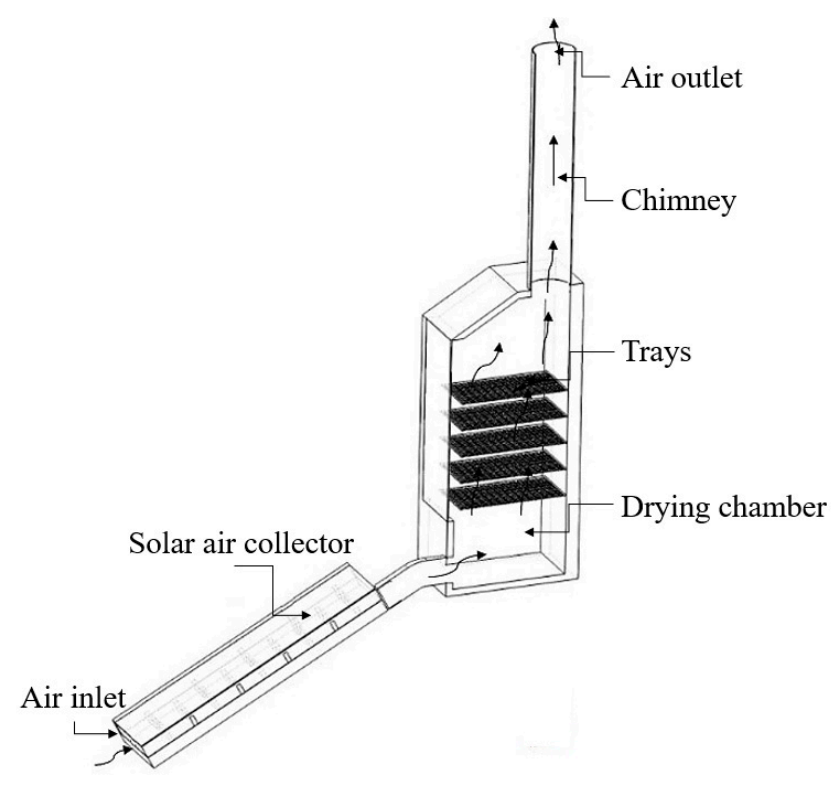

Fig. 1 Experimental setup sunshine hours ranging from $48 \mathrm{~h}$ in December to $274 \mathrm{~h}$ in July (Gödöllő, 2020). The tests were conducted under no-load conditions. The setup comprises a single-pass solar air collector for the purposes of heating the inlet air, a drying chamber for the purposes of maintaining the food dried, and a chimney for the purposes of creating the draft force. It was built with and without a chimney. The solar air collector's external dimensions are $1.2 \times 0.5 \times 0.1 \mathrm{~m}$, and consists of a dark-painted absorber plate, transparent glass and necessary insulation at the bottom. Plexiglass sheet with a thickness of $4 \mathrm{~mm}$ represents the collector glazing for enhancing the drying efficiency. This sheet is UV resistant with good transmissivity. The collector sides and bottom part were insulated with expanded polystyrene (EPS) with a thermal resistance of $1.29 \mathrm{~m} \cdot \mathrm{K} \cdot \mathrm{W}^{-1}$, density of $14.16 \mathrm{~kg} \cdot \mathrm{m}^{-3}$ (Ademović et al., 2017), and thickness of $4 \mathrm{~cm}$ to reduce heat losses during air heating. A copper plate (absorption coefficient $\alpha=0.95$ ) with its top part painted black matt and thickness of $1.5 \mathrm{~mm}$ was employed as the heat absorber plate. According to Duffie and Beckman (2013) and based on the location of the experiment, the tilted angle of the solar collector was $45^{\circ}$ to the horizontal and oriented to the south in order to maximize the solar radiation incident on the collector surface.

The drying chamber was constructed from polystyrene material ( $0.05 \mathrm{~m}$ thickness) with an external dimension of $0.5 \mathrm{~m}$ (length), $0.5 \mathrm{~m}$ (width) and $1 \mathrm{~m}$ (height). The joining between the solar air collector and the drying chamber was made using polyvinyl chloride (PVC) pipe (100 mm inside diameter) with a very low thermal conductivity $\left(0.17 \mathrm{~W} \cdot \mathrm{m}^{-1} \cdot \mathrm{K}^{-1}\right)$ (Ettah et al., 2016). The chamber was fitted with five trays at equal distance $(0.15 \mathrm{~m})$, one above the other, and each tray had $0.5 \mathrm{~m}$ (width) and $0.5 \mathrm{~m}$ (length). These trays were made with wood frames and a fine wire mesh to accommodate the drying material. The drying chamber's roof was built to be slanted in order to improve air velocity.

A PVC pipe was used as the chimney. It had $100 \mathrm{~mm}$ in diameter and $2 \mathrm{~m}$ in height and was firmly attached vertically onto the drying chamber to enhance natural convective air circulation. A duct with an appropriate length was selected for the purposes of ensuring the thermal conditions at chimney outlet. In order to enhance the absorption of solar radiation into the inside of chimney, its external surface was coated with black. The solar radiation, ambient temperature, air velocity, and temperature distribution in the different parts of the system were recorded in interval of every $20 \mathrm{~min}$. The testing point was located on the exterior surface, assuming that the temperature distribution was uniform on the surface, which was reasonable due to the large heat transfer coefficient (Gan and Jang, 2017), as the solar radiation hitting the surface of opaque materials does not transmit the radiation. Ultimately, most of the incident radiation on opaque surfaces will be absorbed.

\section{Experimental methodology}

The air velocity, drying air temperature, and incident solar radiation were all measured during the experiment. The airflow characterization inside the dryer involved the determination of meteorological and flow conditions. The temperatures at the different positions were measured with 


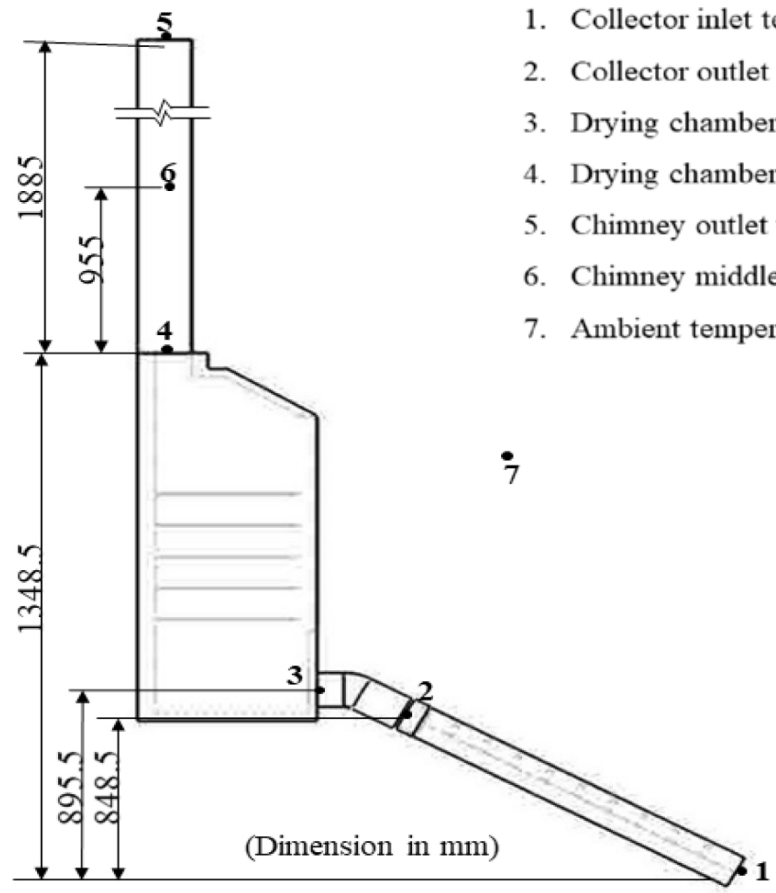

a) solar dryer with chimney
1. Collector inlet temperature, $T_{c, i}$

2. Collector outlet temperature, $T_{c, 0}$

3. Drying chamber inlet temperature, $T_{c h a, i}$

4. Drying chamber outlet temperature, $T_{c h a, o}$

5. Chimney outlet temperature, $T_{c h i, o}$

6. Chimney middle temperature, $T_{c h i, m}$

7. Ambient temperature, $T_{a m b}$

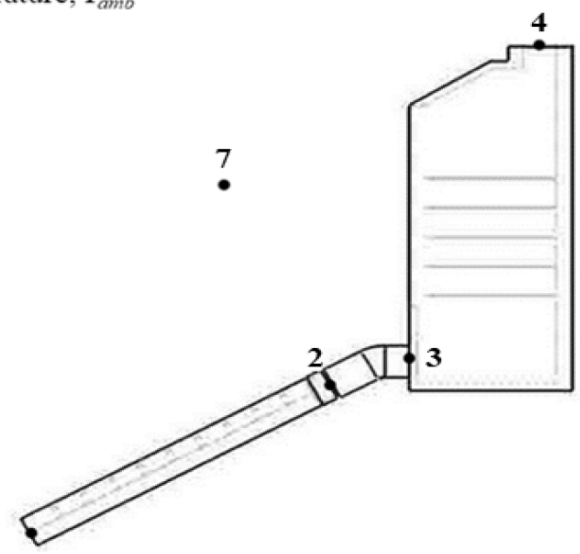

b) solar dryer without chimney

Fig. 2 Positions of the thermocouples at different parts of the dryer

the T-type thermocouples. The measurements were taken at the inlet and outlet of the collector, drying chamber, and chimney (Fig. 2). The temperature probes were preliminary calibrated before starting the actual measurement.

The total solar radiation was measured using a pyranometer. It contained no significant reflecting surfaces, nor it was covered by any shadows during the experimental days. It was at the collector plane. The thermopile was sheltered from the poor meteorological conditions and wind by two transparent hemispherical glass cups. The T-type thermocouples and the solar radiation probe were fitted in the data logger (ADAM 4018), and all the data were recorded automatically. Analogue voltage signals were converted into digital signals in the data acquisition system. A flow meter was utilized to measure the inlet air velocity for the solar air collector. The technical properties of instruments that were used during the experiments are provided in Table 1.

\section{System analysis}

The solar air collector thermal performance is affected by many circumstances, such as air velocity, ambient temperature, solar radiation intensity, air humidity, etc. The amount of solar energy, $I_{T}$, obtained by the tilted collector is estimated as follows (Duffie and Beckman, 2013):

$$
I_{T}=\left[I_{b} R_{b}\right]+I_{d}\left[\frac{1+\cos \beta}{2}\right]+\left[I_{b}+I_{d}\right] r_{g}\left[\frac{1-\cos \beta}{2}\right]
$$

where:

$I_{b}$ - beam radiation; $I_{d}$ - diffuse radiation; $r_{g}$ - diffuse reflectance of the surroundings (usually around 0.25 ); $\beta$ angle between the solar collector and the horizontal plane $\left(45^{\circ}\right) ; R_{b}$ - ratio of beam irradiation on the tilted surface over that on the horizontal plane and can be estimated as in Eqs 2-8. The first term is the beam component, the second term the sky diffuse component, and the third term the radiation reflected from the ground.

Beam radiation value:

$$
I_{b}=I_{H}-I_{d}
$$

Diffusion radiation value:

$$
I_{d}=[1-(1.097 \varepsilon)] I_{H}
$$

Optical factor, $\varepsilon$ :

$$
\varepsilon=\frac{I_{H}}{I_{o}}
$$

\begin{tabular}{|c|c|c|c|}
\hline Instruments & Equipment & Specification & Accuracy \\
\hline Pyranometer & CM-11, Kipp \& Zonen* & $\max : 4000 \mathrm{~W} \cdot \mathrm{m}^{-2}$ & $\pm 3 \%$ \\
\hline Thermocouple & T-type* & $-270^{\circ} \mathrm{C}$ to $370^{\circ} \mathrm{C}$ & $\pm 1.0^{\circ} \mathrm{C}$ \\
\hline Anemometer & EC-MR-330-Eurochron* & $0 \mathrm{~m} \cdot \mathrm{s}^{-1}$ to $30 \mathrm{~m} \cdot \mathrm{s}^{-1}$ & $\pm 0.5 \%$ \\
\hline
\end{tabular}

Table 1 Instruments used for measurement

* technical information is available via the link given at the reference list 
Value of ratio of beam irradiation on the tilted surface over that on the horizontal plane:

$$
R_{b}=\frac{\cos (\theta)}{\cos \left(\theta_{z}\right)}
$$

where:

the numerator is the incidence angle of the solar rays on the tilted surface, and it is related to certain other angles as expressed in Eq. 6:

$\cos \theta=[\sin \delta \sin \varnothing \cos \beta]-[\sin \delta \cos \varnothing \sin \beta \cos \gamma]+$ $[\cos \delta \cos \varnothing \cos \beta \cos \omega]+[\cos \delta \sin \varnothing \sin \beta \cos \gamma \cos \omega]+$ $[\cos \delta \sin \beta \sin \gamma \sin \omega]$

and the denominator is for a horizontal surface, the angle of incidence is the zenith angle of the sun as shown in Eq. 7:

$$
\cos \theta_{z}=[\sin \varnothing \sin \delta]+[\cos \varnothing \cos \delta \cos \omega]
$$

The declination angle of the sun, $\delta$ :

$$
\delta=23.45 \sin \left[360 \frac{284+n}{365}\right]
$$

where:

$I_{H}$ - average horizontal surface radiation value for the actual experimental day $\left(\mathrm{W} \cdot \mathrm{m}^{-2} \cdot\right.$ day $\left.^{-1}\right) ; I_{o}$ - average extra-terrestrial radiation values for the month $\left(\mathrm{W} \cdot \mathrm{m}^{-2} \cdot \mathrm{day}^{-1}\right) ; \theta$ - incidence angle of solar rays on the tilted surface $\left(^{\circ}\right) ; \theta_{z}$ - zenith angle; $\varnothing$ - site latitude $\left({ }^{\circ}\right) ; \gamma$ - azimuth angle $\left({ }^{\circ}\right) ; \omega$ - hour angle measuring from the solar noon $\left({ }^{\circ}\right) ; n$ - number of day 1 for January $1^{\text {st }}$

The variations of $I_{b}$ in a day are known, and $R_{b}$ can be numerically calculated. The amount of solar energy transferred to the collector from the sun can be measured directly with a pyranometer instead of the above complex formulas.

Thermal efficiency is defined as the amount of useful heat gain per time by the solar air collector to the total amount of solar energy received from the sun. The amount of useful heat gain per time, $Q_{u}$ (W) of the solar air collector during the insolation period can be found as:

$$
O_{u}=\dot{m}_{a} c\left(T_{c, o}-T_{c, i}\right)
$$

where:

$\dot{m}_{a}$ - mass flow rate of the air $\left(\mathrm{kg} \cdot \mathrm{s}^{-1}\right) ; c$ - specific heat capacity $\left(\mathrm{J} \cdot \mathrm{kg}^{-1} \cdot \mathrm{K}^{-1}\right) ; T_{c, o}$ and $T_{c, i}$ - collector outlet and inlet temperatures $\left({ }^{\circ} \mathrm{C}\right)$, respectively. The differences between the inlet and outlet collector temperatures can be compared when evaluating the collector performance

The instantaneous collector thermal efficiency can be determined based on the $1^{\text {st }}$ law of thermodynamics as:

$$
\eta_{c}=\frac{\dot{m}_{a} c\left(T_{c, o}-T_{c, i}\right)}{A_{c}(\tau a) I_{T}}
$$

where:

$A_{c}$ - collector area $\left(\mathrm{m}^{2}\right) ; \tau$ - transmissivity of the glazing; $I_{T}$ - hourly solar radiation on the collector surface over a specified period of time $\left(\mathrm{W} \cdot \mathrm{m}^{-2}\right) ; \alpha-$ absorptivity of the absorber plate

\section{Results and discussion}

Knowledge of climatic conditions and availability of solar radiation are prerequisites in solar drying. The experiments were carried out from September $1^{\text {st }}$ to $7^{\text {th }}, 2020$ (10:30 to 15:00). The figures presented in this section were derived from the average of the measured data. The amount of solar radiation, ambient temperature, inlet and outlet temperatures of air in the solar collector, temperatures at various locations of the solar dryer, and airflow velocity were all measured, and results are discussed in this section.

\section{Variation in incident solar radiation and temperatures with time}

Figs $3 a$ and $3 b$ show the overall results of experiments, including the average daily instantaneous solar radiation intensity, ambient temperature $T_{a}$, collector inlet $T_{c i}$ and outlet air temperature $T_{c o}$, and the drying chamber air temperature $T_{\text {cha }}$.

According to Figs $3 a-b$, the solar radiation increases with time until it reaches the highest value at 12:20, as expected. The highest daily solar radiation recorded for

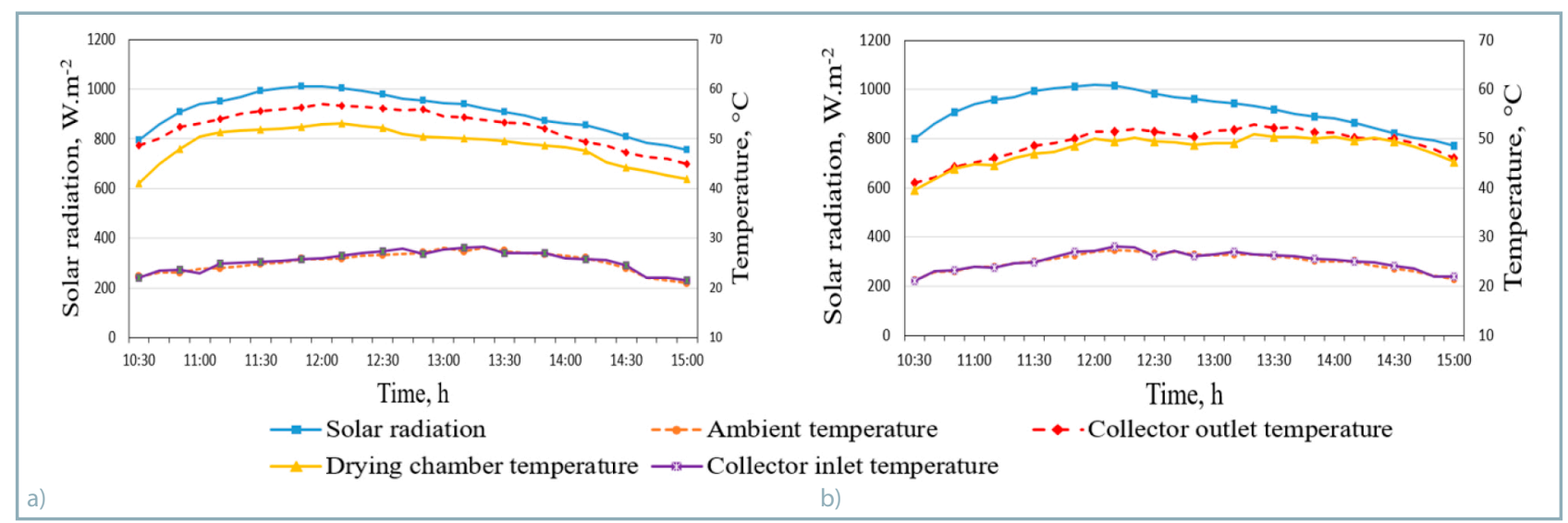

Fig. 3 Instantaneous incident solar intensity and temperature results, a) with chimney; b) without chimney 


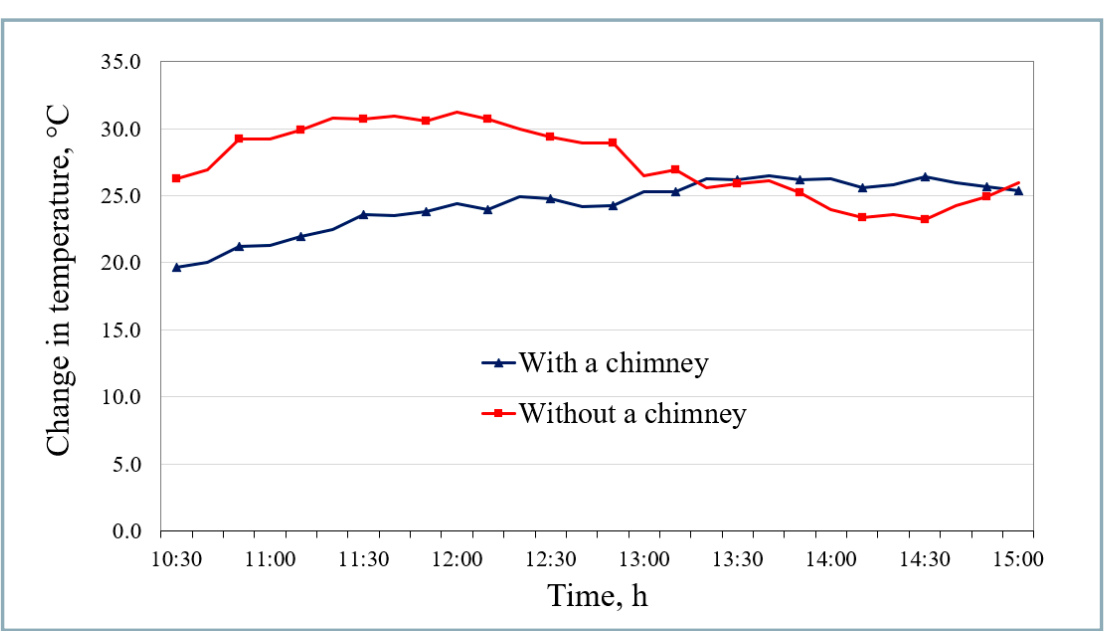

Fig. 4 Variation in the temperature change $(\Delta T)$ in the collector with time

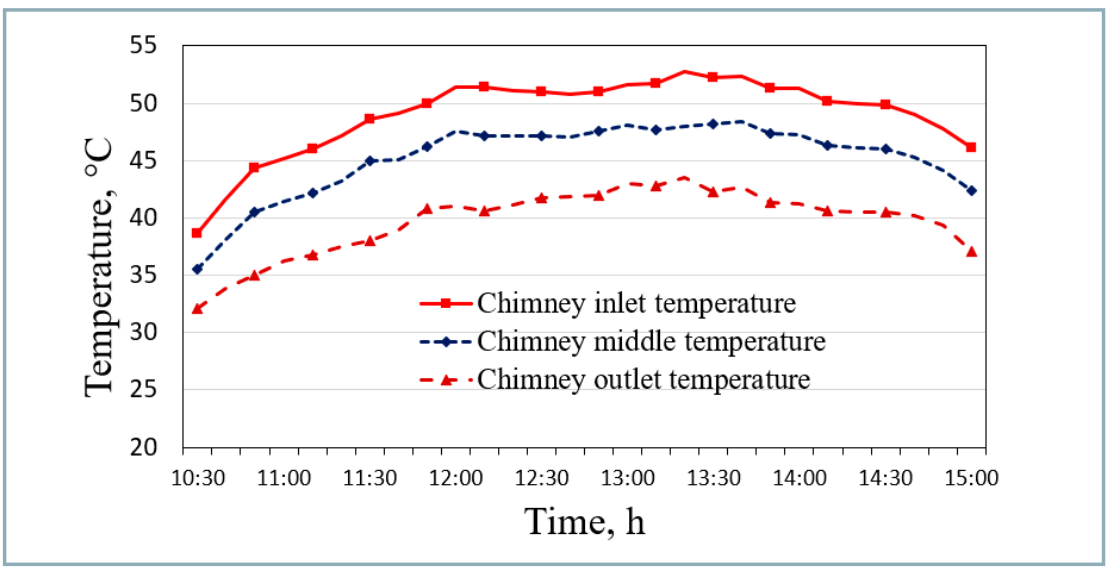

Fig. 5 Variation in chimney temperature with time

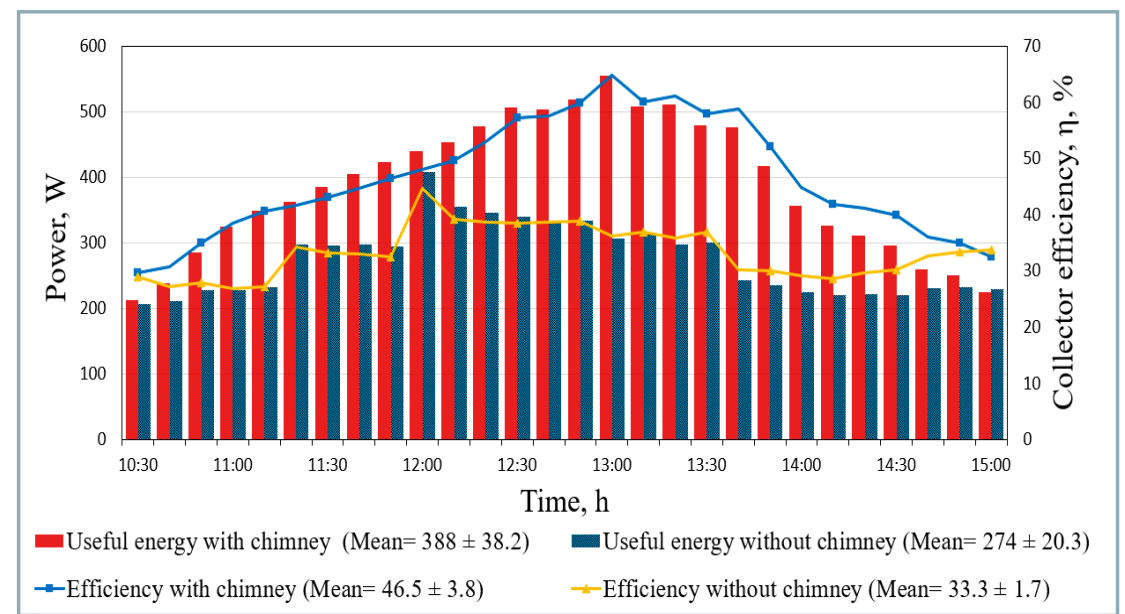

Fig. 6 Variation in useful heat gain and collector efficiency with time the chimney dryer was $1018 \mathrm{~W} \cdot \mathrm{m}^{-2}$ and $1012 \mathrm{~W} \cdot \mathrm{m}^{-2}$ for the dryer without a chimney. The ambient temperature was between $21{ }^{\circ} \mathrm{C}$ and $28^{\circ} \mathrm{C}$. The ambient temperature $T_{a}$, collector outlet temperature $T_{c o}$ and drying air temperature $T_{\text {cha }}$ exhibited the same behaviour as solar radiation intensity they attained their maximum values of $27{ }^{\circ} \mathrm{C}, 52.8^{\circ} \mathrm{C}$ and $50.8^{\circ} \mathrm{C}$ between 12:00 to $13: 00$ for the chimney dryer, and $28^{\circ} \mathrm{C}, 57^{\circ} \mathrm{C}$ and $53^{\circ} \mathrm{C}$ for the dryer without a chimney.

Figures $3 a-b$ clearly illustrate that when the solar radiation increases, ambient temperature and temperature inside the dryer also increase, indicating that the ambient air temperature and the temperature inside the system are both highly influenced by the solar radiation intensity. It can be observed that a chimney integrated dryer was $6{ }^{\circ} \mathrm{C}$ lower than the dryer without a chimney. However, the air velocity in this dryer was enhanced by approx. $57 \%$ in contrast to the dryer without a chimney. The reason for the increase in airflow can be attributed to the buoyancy effect. The trends in the behaviour of the curves (Fig. 3) are in agreement with the results of Prasartkaew and Kumar (2014). The measured collector outlet temperature in both cases was below $60^{\circ} \mathrm{C}$, which is typical for flat-plate solar air collectors (Gupta and Kaushik, 2008). Moreover, experimental results demonstrated a better agreement when the collector inlet temperature is close to the ambient temperature.

Figure 4 depicts the variation in the temperature change in the collector with and without a chimney with time. It was observed that there was less fluctuation and more uniformity in the temperature range for the chimney integrated solar dryer. This result reveals that the presence of a chimney in solar dryer enhances the airflow rate and retains the uniformity of the temperature inside the dryer.

Figure 5 illustrates the chimney temperature development at three different heights during the experimental time. The maximum temperature for the chimney inlet, middle and outlet reached $51.3{ }^{\circ} \mathrm{C}$ at $13: 20,48.4{ }^{\circ} \mathrm{C}$ at $13: 40$ and $43.5^{\circ} \mathrm{C}$ at $13: 20$, respectively. It was expected that areas closer to the collector would reach higher temperatures 
Table 2 Correlation between solar radiation and collector efficiency

\begin{tabular}{|l||c|c|}
\hline \multicolumn{1}{|c||}{} & Dryer with chimney & Dryer without chimney \\
\hline Observation & 28 & 28 \\
\hline Degree of freedom & 26 & 26 \\
\hline Significance F (P-value) & 0.001969 & 0.004599 \\
\hline Coefficient & 0.076879 & 0.032045 \\
\hline Standard error & 0.022341 & 0.010334 \\
\hline
\end{tabular}

(Nasri, 2020). The relative magnitude of temperature in the chimney gives an indication of airflow through the dryer. Figure 5 also shows that the chimney's outlet temperature values (between $32{ }^{\circ} \mathrm{C}$ and $43^{\circ} \mathrm{C}$ ) were much greater than the ambient temperature.

\section{Determination of collector efficiency}

Figure 6 illustrates the rate variation of useful heat gain and the instantaneous collector efficiency with experiment time. The energy efficiency was used to evaluate the solar air collector performance. The total heat gain and the thermal efficiency available for the collector were estimated using Eqs 9 and 10, respectively. As expected, both rate of heat gains and efficiency increased from the morning to a certain peak value and started to decrease in the afternoon till the end of experiment. It had the same trend for the incident as for solar radiation. This result shows that thermal efficiency and useful heat gain depend on the solar radiation intensity. The heat gained varied from 213.4 W to $554.9 \mathrm{~W}$ for the chimney integrated dryer and from $207 \mathrm{~W}$ to $408 \mathrm{~W}$ for the dryer without a chimney. The collector heat gain was improved by approx. $35 \%$ by employing the chimney in contrast to state without it. According to Fig. 6, the collector efficiency with and without using a chimney varied from $30 \%$ to $65 \%$ and from $27 \%$ to $45 \%$, respectively. The mean thermal efficiency of the dryer with the chimney was $30 \%$ higher than the dryer without a chimney due to the increase in the air flow rate in the drying system enhanced by the chimney. Chabane et al. (2014) also observed a similar result and reported that the increase in airflow rate has a significant impact on the collector efficiency. The collector efficiency corresponding to the solar radiation was estimated using excel data analysis (ANOVA) at a 95\% confidence level. A total of 28 data (observation) was taken into account. The number of variables that needed to be estimated in order to complete a data set is explained by the degree of freedom. Standard error also explains the precision with which the regression was measured. Coefficients are the values that multiply the predictor values. Results shows a significant positive relationship between solar radiation and collector efficiency, as shown in Table 2.

\section{Conclusions}

The study presented was undertaken to experimentally investigate the thermal performance of a solar air collector with natural convection airflow using a chimney. When a well-designed chimney was incorporated with the solar dryer application, the collector efficiency improved. The working principle of a chimney is to enhance the airflow velocity by creating a buoyancy effect. It is recommended that the temperature difference between the mean temperature inside the chimney and the ambient temperature should be high to enhance the airflow rate. According to the study, when a chimney is employed in the drying system, there is less fluctuation and more uniformity in the temperature range. The values of the heat gain rate and the collector efficiency are both comparatively higher when using a chimney. Due to the system's integrated chimney, the collector efficiency improves as airflow rate increases, while the air temperature difference between the inlet and outlet decreases. As a result, solar intensity and air mass rate have a significant impact on the collector thermal efficiency. This paper will be beneficial to all interested researchers in improving the efficiency of the solar drying system with chimney integrated solar dryers.

\section{Acknowledgements}

The authors acknowledge for the support of the Stipendium Hungaricum Programme and the Doctoral School of Mechanical Engineering, Hungarian University of Agriculture and Life Sciences, Gödöllő, Hungary.

\section{References}

ADEMOVIĆ, Z. - SULJAGIĆ, J. - ZULIĆ, J. 2017. Influence of physical properties on thermal conductivity of polystyrene insulation materials. In Contemporary Materials, vol. 8, no. 1, pp. 42-47.

AFRIYIE, J. K. - NAZHA, M. A. - RAJAKARUNA, H. - FORSON, F. K. 2009. Experimental investigations of a chimney-dependent solar crop dryer. In Renewable Energy, vol. 34, no. 1, pp. 217-222.

ALDABBAGH, L. B. Y. - EGELIOGLU, F. - İLKAN, M. 2010. Single and double pass solar air heaters with wire mesh as packing bed. In Energy, vol. 35, no. 9, pp. 3783-3787.

BOUHDJAR, A. - SEMAI, H. - BOUKADOUM, A. - ELMOKRETAR, S. MAZARI, A. - SEMIANI, M. - AMARI, A. 2020. Improved procedure for natural convection garlic drying. In Acta Technologica Agriculturae, vol. 23, no. 2, pp. 92-98.

CHABANE, F. - MOUMMI, N. - BENRAMACHE, S. - BENSAHALI, D. BELAHSSEN, O. 2013. Collector efficiency by single pass of solar air heaters with and without using fins. In Engineering Journal, vol. 17, no. 3, pp. 43-55.

CHABANE, F. - MOUMMI, N. - BENRAMACHE, S. 2014. Experimental study of heat transfers and thermal performance with longitudinal fins of solar air heater. In Journal of Advanced Research, vol. 5, no. 2, pp. 183-192.

DUFFIE, J. - BECKMAN, W. 2013. Solar Engineering of Thermal Processes. Chapter 1. Solar Radiation. New Jersey, USA : John Wiley and Sons, pp. 3-41. ISBN 9781118671603.

EL-SEBAII, A. A. - ABOUL-ENEIN, S. - RAMADAN, M. R. I. - EL-BIALY, E. 2007. Year round performance of double pass solar air heater 
with packed bed. In Energy Conversion and Management, vol. 48, no. 3, pp. 990-1003.

EL-SEBAII, A. A. - ABOUL-ENEIN, S. - RAMADAN, M. R. I. - ELGOHARY, H. G. 2002. Experimental investigation of an indirect type natural convection solar dryer. In Energy Conversion and Management, vol. 43, no. 16, pp. 2251-2266.

ETTAH, E. B. - EGBE, J. G. - TAKIM, S. A. - AKPAN, U. P. - OYOM, E. B. 2016. Investigation of the thermal conductivity of polyvinyl chloride (PVC) ceiling material produced in Epz Calabar, for application tropical climate zones. In Journal of Polymer and Textile Engineering, vol. 3, no. 2, pp. 34-38.

EUROCHRON EC-MR330 Operating Instructions Manual. 2021. Available at: https://www.manualslib.com/manual/1868689/ Eurochron-Ec-Mr330.html (Accessed: 1 June 2021).

GÖDÖLLŐ. 2020. Available at: Wikipedia. https://en.wikipedia.org/ wiki/Godollo\#\%20climate (Accessed: 27 October 2020).

GAN, Y. F. - JANG, J. Y. 2017. Optimal heat transfer coefficient distributions during the controlled cooling process of an $\mathrm{H}$-shape steel beam. In Advances in Materials Science and Engineering, vol. 2017, article no. 873283.

GUPTA, M. K. - KAUSHIK, S. C. 2008. Exergetic performance evaluation and parametric studies of solar air heater. In Energy, vol. 33, no. 11, pp. 1691-1702.

HABTAY, G. - FARKAS, I. 2019. Heat transfer calculation of chimney applied for indirect solar dryer. In Proceedings of $7^{\text {th }}$ European Drying Conference 2019. Torino : Politecnico di Torino, pp. 128-132.

KARIM, M. A. - HAWLADER, M. 2004. Development of solar air collectors for drying applications. In Energy Conversion and Management, vol. 45, no. 3, pp. 329-344.

KIPP-MAN-CM11 PYRANOMETER. 2021. Available at https://www.kippzonen.com (Accessed: 1 June 2021).

LINGAYAT, A. - CHANDRAMOHAN, V. P. - RAJU, V. R. K. 2017. Design, development and performance of indirect type solar dryer for banana drying. In Energy Procedia, vol. 109, pp. 409-416.
LINGAYAT, A. - CHANDRAMOHAN, V. P. - RAJU, V. R. K. - KUMAR, A. 2020. Development of indirect type solar dryer and experiments for estimation of drying parameters of apple and watermelon. In Thermal Science and Engineering Progress, vol. 16, pp. 100477. MADHLOPA, A. - JONES, S. A. - SAKA, J. K. 2002. A solar air heater with composite-absorber systems for food dehydration. In Renewable Energy, vol. 27, no. 1, pp. 27-37.

NASRI, F. 2020. Solar thermal drying performance analysis of banana and peach in the region of Gafsa (Tunisia). In Case Studies in Thermal Engineering, vol. 22, pp. 100771

OMOJARO, A. P. - ALDABBAGH, L. B. Y. 2010. Experimental performance of single and double pass solar air heater with fins and steel wire mesh as absorber. In Applied Energy, vol. 87, no. 12, pp. 3759-3765.

ONG, K. S. - CHOW, C. C. 2003. Performance of a solar chimney. In Solar Energy, vol. 74, no. 1, pp. 1-17.

PARIKH, D. - AGRAWAL, G. D. 2012. Solar drying in hot and dry climate of Jaipur. In International Journal of Renewable Energy Research, vol. 1, no. 4, pp. 224-231.

PRASARTKAEW, B. - KUMAR, S. 2014. Design of a renewable energy based air-conditioning system. In Energy and Buildings, vol. 68, pp. 156-164.

RAMANI, B. M. - GUPTA, A. - KUMAR, R. 2010. Performance of a double pass solar air collector. In Solar Energy, vol. 84, no. 11, pp. 1929-1937.

SSEWANGA, M. - MAKULE, E. - KAYONDO, S. I. 2020. Performance analysis of an improved solar dryer integrated with multiple metallic solar concentrators for drying fruits. In Solar Energy, vol. 204, pp. 419-428.

TYPE T THERMOCOUPLE. 2021. Available at: https://tempsens.com/blog/type-t-thermocouple (Accessed: 1 June 2021). 